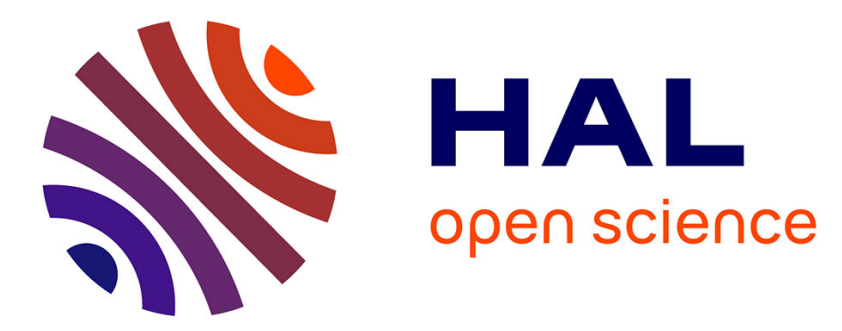

\title{
The emergence of expressive options in early child language: a constructivist account.
}

Edy Veneziano

\section{To cite this version:}

Edy Veneziano. The emergence of expressive options in early child language : a constructivist account.. D. Ravid \& H. Bat-Zeev Shyldkrot. Perspectives on language and language development: Essays in honor of Ruth A. Berman, Springer, Dordrecht, pp.203-218, 2004. halshs-00130511

\section{HAL Id: halshs-00130511 https://shs.hal.science/halshs-00130511}

Submitted on 12 Feb 2007

HAL is a multi-disciplinary open access archive for the deposit and dissemination of scientific research documents, whether they are published or not. The documents may come from teaching and research institutions in France or abroad, or from public or private research centers.
L'archive ouverte pluridisciplinaire HAL, est destinée au dépôt et à la diffusion de documents scientifiques de niveau recherche, publiés ou non, émanant des établissements d'enseignement et de recherche français ou étrangers, des laboratoires publics ou privés. 


\section{THE EMERGENCE OF EXPRESSIVE OPTIONS IN EARLY CHILD} LANGUAGE: A CONSTRUCTIVIST ACCOUNT

EDY VENEZIANO

Université Paris 5-CNRS, France

\section{INTRODUCTION}

As Berman and Slobin (1994) point out, there are different ways of relating the "same" events and, as soon as these are structurally available, they exist for the speaker as "expressive options".

The notion of expressive options can be considered a universal characteristic of language as well as a fundamental acquisition for language learners. Having expressive options implies to consider different formulations as somehow related one to another, be it under commonality of meaning, of communicative function, or simply of referentiality. Previously constructed signifier-signified and form-function relations change in status by being embedded into an array of co-possible alternatives, as the meaning of individual items is colored, limited or enriched by that of other individual items belonging to the same system. In this perspective, the acquisition of expressive options can also be seen as linked to the very notion of language as an overall system.

For the narrative genre, Berman \& Slobin, and other researchers who collected "frog" stories from children speaking different languages (English, Hebrew, German, Turkish, Spanish, and other languages have followed the original project), have shown that children acquire new linguistic forms and use them first for old and then for new functions. More crucially, however, they have shown that children become progressively better able to organize these linguistic forms into sets of co-possible formulations and to use them accordingly. In choosing one of these formulations, children can select, upgrade or downgrade aspects of events, connect them in different ways, and realize 
their communicative goals taking into account the beliefs and perspectives of their listeners. In their functional approach, language knowledge requires thus much more than acquiring structures and forms. Progress in the construction of coherent narratives depends on cognitive, communicative and linguistic developments. Cognitively, children need to grasp the entities and relations they are going to talk about; communicatively, they need to make distinctions among the states of knowledge and feelings of the characters, of the narrator and of the listener; linguistically, they have to acquire the necessary forms, lexical, morphological and syntactic, to express contents and perspectives. The integration of these strands contributes to determine the expressive options that children have at their disposal at various developmental levels.

Here I would like to consider the notion of expressive option from the point of view of its emergence, by looking for possible antecedents and early manifestations of this capacity, and to consider the directions in which they develop.

\section{Expressive options and mentally-entertained possibilities}

I will propose that the emergence of this ability may be related in a deep way to children's cognitive development and, in particular, to the mechanisms that allow the subject to entertain different possibilities at the same time. Conceptually, to have expressive options means to be able to consider simultaneously different expressions as possible alternative ways for talking about the "same" event, or the "same" communicative intention. And indeed, in one of his latest work, Le possible et le nécessaire (Possibility and necessity), Piaget (1981/1987) has looked at cognitive development from the point of view of a growing ability to conceive alternatives or new possibilities ("les possibles"), and to view them as simultaneously possible. Knowledge of an entity or event is greater if the child can see it as the actualization of one possibility among a set of other possibilities. A particular event becomes embedded in a larger network of possible events that were not realized. Such a mental construction of the world is considered by Piaget as a characteristic feature of constructivism, as compared to empiricism. Indeed, looked at in this way, knowledge, is not viewed simply as a better representation of the objective "world", but as the mental construction of co-possible worlds in which what is actualized gets part of its meaning in relation to the co-possible set of alternatives, that is, to what is not but could have been.

For Piaget, possibilities do not grow only in number but also, and more crucially, with children's growing representational abilities, they change in status. At first, alternatives are considered successively ("les possibles successifs"); then, they are anticipated simultaneously and viewed as co-possible alternatives. The anticipated possibilities are based at first on what has been already realized ("les co-possibles concrets"); then they become more abstract possibilities deriving from the properties of the system they are part of ("les possibles abstraits" et "déductifs"). In the work cited, Piaget \& coll. have studied children from 4 to 12 years of age. Piaget however emphasizes that the developmental mechanisms leading to the construction of new possibilities, is at work since the sensorimotor period, at least as far as the two early forms are concerned: The possibilities considered successively, and the concretely-based, simultaneously-anticipated possibilities. 
In what follows I will suggest that the first alternative expressions consist of successively-centered perspectives. Then, when alternative expressions start to be anticipated simultaneously and mentally considered as co-possibilities, at this early stage, two kinds of outcomes may result: 1 . Simultaneously anticipated alternatives are viewed as a set of options among which to choose one expression considered better adapted to the situation at hand (the "alternative expressive options" outcome); 2. Simultaneously anticipated alternatives combine to enrich the expression of one given communicative intention, and are coordinated into a higher level structural unit (the "combined options" outcome). This higher level unit can then become a new possibility in a set of alternative expressive options.

To provide empirical support to these hypotheses, I will consider below developments in the child's expression of recurring very similar communicative acts, in the verbalization of aspects of request and oppositional acts, and the expression of one and the same communicative act at the transition from single to multiword speech. The material discussed below has been drawn from longitudinal studies of Frenchacquiring children for which extensive analyses of lexical, early combinatorial and pragmatic developments have been performed (e.g., Veneziano, 1999a, 1999b, 2001; Veneziano \& Sinclair, 1995, 2000). These children, studied between the ages of 1;3 and $2 ; 4$, were in the late single word and early two-word utterances period of verbal expression.

\section{EXPRESSIVE ALTERNATIVES FOR RECURRING SIMILAR COMMUNICATIVE INTENTIONS}

When children express, within a short time period, very similar communicative intentions, do they use, from one episode to the next, the same verbalizations or do they use different ones? Earlier studies have reported that children tend to use first one verbal form or one conversational principle (for example repeating part of the preceding utterance) for expressing a given communicative intent, while later they start to use different verbalizations to talk about similar events or communicative intentions (e.g. Antinucci \& Parisi, 1973; Barrett, 1981; Clark, 1997; Greenfield \& Smith, 1976; Halliday, 1975; Ninio, 1994; Veneziano 1990, 1999a). In earlier work the units of analysis were speech acts (e.g., requesting and asserting) or more narrowly-defined functions that could nevertheless concern different situations. For example, Ninio (1994) considered communicative intents like "initiating joint activity on a focused object" in which the activity and the focused object depend on the specific situations in which they occur. In this context, Ninio and Snow (1996) describe a developmental trend that goes from the use of constant forms (like 'this') to that of variable forms, the latter being forms reflecting the particularities of the situation at hand.

Here, in order to throw some light more directly on the question of the emergence of expressive options, we have investigated whether variety of expression is observed when only events that are very similar to each other are taken into account, and whether the occurrence of expressive variety is a developmental phenomenon, both in terms of its emergence and in terms of its frequency and internal variety. That is, does the phenomenon grow relatively to the number of recurring episodes that 
Table 1. Verbalization of recurrent communicative intentions/events, by age

\begin{tabular}{|c|c|c|c|c|c|}
\hline $\begin{array}{l}\text { Age of the } \\
\text { child at } \\
\text { session }\end{array}$ & $\begin{array}{l}\text { Number of recurrent } \\
\text { intentions/events } \\
\text { identified and total } \\
\text { number of occurrences } \\
\text { in parentheses }\end{array}$ & $\begin{array}{l}\text { Number (and \%) of } \\
\text { recurrent intentions/ } \\
\text { events expressed by } \\
\text { different single-word } \\
\text { utterances }\end{array}$ & $\begin{array}{l}\text { Number of different } \\
\text { words produced } \\
\text { per type of } \\
\text { intention }\end{array}$ & $\begin{array}{l}\text { Mean number } \\
\text { of expressions } \\
\text { per type of } \\
\text { intention/ } \\
\text { event }\end{array}$ & $\begin{array}{l}\text { Cumulative } \\
\text { vocabulary: } \\
\text { types }\end{array}$ \\
\hline $1 ; 3.16$ & $4(13)$ & $0(0 \%)$ & 0 & 1.00 & 18 \\
\hline $1 ; 4.26$ & $9(29)$ & $2(22.2 \%)$ & $2 ; 2$ & 1.22 & 30 \\
\hline $1 ; 5.23$ & $10(44)$ & $4(40 \%)$ & $4 ; 2 ; 3 ; 2$ & 1.70 & 52 \\
\hline $1 ; 6.22$ & $8(41)$ & $6(75 \%)$ & $2 ; 2 ; 2 ; 3 ; 3 ; 3$ & 2.13 & 67 \\
\hline
\end{tabular}

are expressed in different manners, and to the number of different expressions used for set of recurrences? The answers to these questions have been looked for in the longitudinal data of one French-acquiring child studied between 1;3 and 2;2.

The episodes have been selected by applying two restrictions. First, in order to ensure a maximum of similarity among the recurring events, we considered only narrowlydefined communicative events that occurred at least twice during the same session. For example, each of the following were counted as different events/communicative intentions: showing a spinning top, making a request to have a spinning top turn, making a request to take plastic beads apart, and offering a baby doll. Second, in order to capture very early manifestations of the child's use of expressive alternatives, we have included only events occurring before the appearance of two-word utterances, expressed essentially by single-word utterances and sometimes by SSWUs ${ }^{1}$.

Through the analysis of videotapes of naturally occurring interaction, registered at the child's home at bimonthly intervals (about one hour per observational session, for a total of about 16 hours of videorecordings), we found that recurrent communicative events corresponding to the above criteria occur between $1 ; 3$ and 1;7. As can be seen in Table 1, the use of different single-word utterances to verbalize recurrent instances of similar communicative events is first observed at $1 ; 4.26$, and increases with age, both in terms of the number and of the proportion of recurring events that find different expressions.

At 1;3.16, none of the four recurring types of communicative events are expressed with different words. For example, the child handed a baby doll to the adult five different times during the observational session, and each time she said /ta/ tiens 'take (it). At 1;4.26, of the nine types of events occurring at least twice, seven were, on each occasion, expressed with the same word. For example, the child asked on five different occasions to pull apart a chain of plastic beads and each time she expressed this request by saying maman 'mommy'. Two types of events (22\%), however, were expressed with different words. One type consists in a request for must ${ }^{2}$, expressed three times by /mu:/ or /lu:'u:/ moût 'must', and once by /ko/ encore, 'again/more'; the other type of event - pointing towards Geneva's 'water jet', visible at a distance - occurred four

\footnotetext{
${ }^{1}$ Successive single-word utterances (SSWUs) will be treated in greater detail later in this paper where we consider specifically cases in which the child produces different verbalizations to talk about one and the same event or intention.

2 'Must' is "the expressed juice of grapes ... before and during fermentation" (Webster's Dictionary).

${ }^{3}$ The Water Jet is a town's curiosity towering over the Lake of Geneva. It is 145 meters high and visible from a great distance.
} 
times, and was expressed twice by /la/ là 'there' and twice by /do/ for jet d'eau /jedo/, 'water jet'. At 1;5.21, among the ten types of recurring events identified, four (40\%) were expressed differently. For example, a game in which the child stepped up and then came down from a trunk was repeated eight times in succession. Before stepping up, the child twice said /ã'o/ en haut 'up', five times /ko/ encore, 'again/more', and once /sot/ saute, 'jump'. Another type consists in a request to turn the key of a mechanical frog, a request that the child addressed on six different occasions to her mother. Each time she handed the frog to the mother and, while doing that, on three occasions she said /ta/ tiens 'take (it)', in another, /ko/ encore, 'again/more', in another /gu/ grenouille 'frog', and in yet another /tu/tourne 'turn'. At 1;6.22, six of the eight types of recurring communicative events (75\%) were expressed differently. One of them re-occurred six times. Each time the child was trying to seat a baby doll on the carpet: on three occurrences, she said /la/ 'there', twice, assis 'seated' and once $/ \mathrm{la} \#^{4}$ a'si/.

In the period between 1;3 and 1;7 there is also an increase in the variety of verbal expressions used, as indicated by the fact that the mean number of word types produced per type of communicative event increases with age (see Table 1): in three and a half months it increases steadily from 1 to 2.13 , passing by 1.2 and 1.7 .

These results point out that the child has at her disposal progressively more expressions to talk about a given communicative intention or event, and that on different occasions, she uses one or the other of them, capturing different aspects of the event. There is no indication, at this time, that these alternative expressions are more than the verbalization of successive centers of attention and we suppose that that they do not constitute yet simultaneously entertained options from which to choose.

It may be supposed that if lexical availability is certainly necessary to produce, successively, different verbalizations in very similar intentions and events, it may not be sufficient to set the process in motion. Indeed, the first occurrences of expressive variety for a given communicative act type are observed only at 1;4.26, when cumulative vocabulary counts already at least 30 words (see Table 1). Analyses of the rate of lexical growth shows that, although the cumulative vocabulary increases in an accelerated way throughout the period between $1 ; 3$ and 2;2, a significantly larger acceleration is observed at 1;5.23 and at 1,10.22 (Veneziano, 1999a). The spurt in vocabulary at $1 ; 5.23$ corresponds to the time when successive alternative expressions become more frequent and diversified per type of event, in support of the hypothesis that these two developments are related and sustain one another.

\section{EXPRESSIVE ALTERNATIVES FOR RECURRING COMMUNICATIVE ACTS: THE CASE OF REQUESTS, OPPOSITIONS AND THEIR JUSTIFICATIONS}

Another phenomenon, conceptually close to the one just considered, has been encountered in the study of the emergence of justifications (Veneziano \& Sinclair, 1995; Veneziano, 1999b). The early occurrences of verbalizations satisfying the criteria of justifications where found often within requests and oppositional communicative acts, after the latter were expressed in various other ways.

\footnotetext{
${ }^{4}$ The symbol \# indicates a silence greater than 0.5 seconds and less or equal to 1 second.
} 


\section{The expression of request and oppositional acts}

Analyses of the longitudinal studies of four mother-child dyads have shown that requests and oppositions occur at all observational sessions from the beginning of the studies (Veneziano \& Sinclair, 1995). For requests, we found that there was a first period in which children verbalized one or another of the different aspects of the request: the desired object (e.g., / $\int \tilde{o} /$ for bouchon, 'bottlecap', while reaching out towards the mother who held a bottlecap); the desired result (e.g., /ecru/ for trou, 'hole', while handing a punching machine and a piece of paper to the mother); the person solicited (e.g. /mamã/ ,'mommy', while handing a spinning top to the mother) or the action that should be carried out so that the child can obtain the desired object, state or result (e.g., /ovi/ for ouvrir 'open', while handing a box containing baby dolls to the mother; /tun/ for tourne, 'turn', while handing a spinning top to the mother for making it turn). At some point in development a new behavior appeared: while performing the gestures that allowed their communicative act to be identified as a request, children, instead of verbalizing a component of the request, provided the reason for making the request, justifying for their interlocutor the act itself of making a request. For example, one child, handing the mother a box containing baby dolls she wanted to take out, said /e'pa/, (peux) pas, 'can't'; another child, handing his mother a videocassette holder said /e'dy/, (c'est) dur, '(it's) hard', and yet another child, handing her mother a doll, after having unsuccessfully tried to remove her pants, said /e'pa/, (peux) pas, 'can't'.

Also for oppositional acts, be them protests, refusals, or denials, we found that there was a period in which children expressed them by saying non, accompanied or not by an action manifesting opposition, and sometimes, for protests and refusals, only by an action (e.g., the child placed her hair the way it was before her father changed its position; another child turned her head away after the mother's proposition to taste a drink "t'en veux ?" 'do you want it?'). Then, at a certain point in development, children started to provide a justification for their opposition. For example, Chantal at 1;6 refused her mother's help and said non; then, immediately afterwards, while looking at her mother before resuming her activity, added /tusel/, toute seule, 'all by myself'; Gael, at 1;10.17, by saying non, refused the adult's suggestion to build a train and immediately added, looking at the adult, bebe 'baby', indicating what he would like to do instead; it was not till later that he went to the toybag to look for baby dolls.

Providing a justification of these communicative acts is taking up a completely new perspective on the situation. Instead of solely concentrating on oneself, on one's desires and intentions, the child lets the interlocutor's point of view enter the expression of the act, funneling his intentions and desires through those of the interlocutor's: a request to satisfy one's intention adds now an element that works on the addressee's own intentions, anticipating his possible refusal; and a refusal adds a verbal expression that, while letting through one's intention, acknowledges the interlocutor's different one.

As can be seen in Table 2, although requests and oppositional acts are produced from the beginning of the studies, it is only at a certain point in development, slightly varying for each child (around 1;6 for the earliest and 1;9 for the latest), that justifications are provided in these contexts. 
Table 2. Proportion of communicative acts of requests and of oppositions presenting a justification, by child, at two developmental periods

\begin{tabular}{|c|c|c|c|c|c|c|c|c|}
\hline Age of the & \multicolumn{2}{|c|}{ CAM } & \multicolumn{2}{|c|}{ CHAN } & \multicolumn{2}{|c|}{ AMA } & \multicolumn{2}{|c|}{ GAE } \\
\hline child & $1: 3-1 ; 7 ; 4$ & $1 ; 7 ; 18-1 ; 10$ & $1 ; 4-1 ; 5$ & $1 ; 6 .-1 ; 8$ & $1 ; 5-1 ; 7$ & $1 ; 8-2 ; 0$ & $1 ; 4-1 ; 8$ & $1 ; 9-2 ; 3$ \\
\hline Requests & $0 \%$ & $35.5 \%$ & $0 \%$ & $14.3 \%$ & $0 \%$ & $3,7 \%$ & $0 \%$ & $15 \%$ \\
\hline Oppositions & $0 \%$ & $68.2 \%$ & $0 \%$ & $16,1 \%$ & $0 \%$ & $24,2 \%$ & $0 \%$ & $25.0 \%$ \\
\hline
\end{tabular}

Justifications are not produced with the same frequency by the four children (Camille producing more justifications in these contexts than the other children) but all the children verbalize them and all produce them proportionally more in oppositional than in request acts. As it was noticed earlier for the appearance of expressive variety in recurring types of communicative acts, also the appearance of justifications cannot be ascribed simply to children's acquisition of new lexical items. Indeed, children know already some of the words later used to justify requests but do not use them for justification purposes but, for example, to express difficulties in reaching their goal ('can't' or 'hard'). In the case of oppositions, the words used to provide justifications of protests, refusals and denials can be words like 'mommy' and 'baby' that are part very early on of children's lexical repertoire (Veneziano \& Sinclair, 1995).

\section{A zoom on one longitudinal study}

Table 3 presents data for the expression of requests, subdivided into requests for objects, actions/results, and general help, and of oppositions, differentiated into protests, refusals and denials. Verbal expressions are here considered in relation to components of the communicative acts and not in terms of the specific words used, which they depend on the kind of request or oppositional acts that are specifically realized in the context.

It can be seen that it is at 1;4.26 that the child starts to give verbal expression to various components of her requests for actions or results ${ }^{5}$. At this session this kind of request occurs 16 times, 12 of which verbalize the person solicited ('mommy', a vocative for attention, or the "agent" of the request), 3 the desired action/result ('turn') and one the repetition of the event ('more'). From this point onwards, expressive variety is always observed. Moreover, with age, some further components of the request are verbalized (the action of giving the object and the beneficiary of the object requested) and there is a greater variety in the words used to verbalize each of the components (an expansion that is particularly evident for the action/result component). At 1;7.18 justifications of requests appear, making for example reference to the child's incapacity to obtain the desired object or result, or to what the child is going to do with the requested object (e.g., that the requested water is for the baby). Oppositions, that until $1 ; 8$ are essentially protests and refusals, when verbalized, always express the opposition by the negative particle 'no'. Starting at 1;5, other components are also verbalized: the

\footnotetext{
${ }^{5}$ Actions and results cannot often be distinguished as in several cases the action requested is also resultative as for example
} in the case of tourne 'turn', and ouvre 'open'. 
\begin{tabular}{|lrcc} 
P1: MRM/SJS & P2: MRM/SJS & QC: MRM/SJS & T1: MRM \\
KI076-15 & September 15, 2004 & $16: 24$ & Char Count $=0$
\end{tabular}

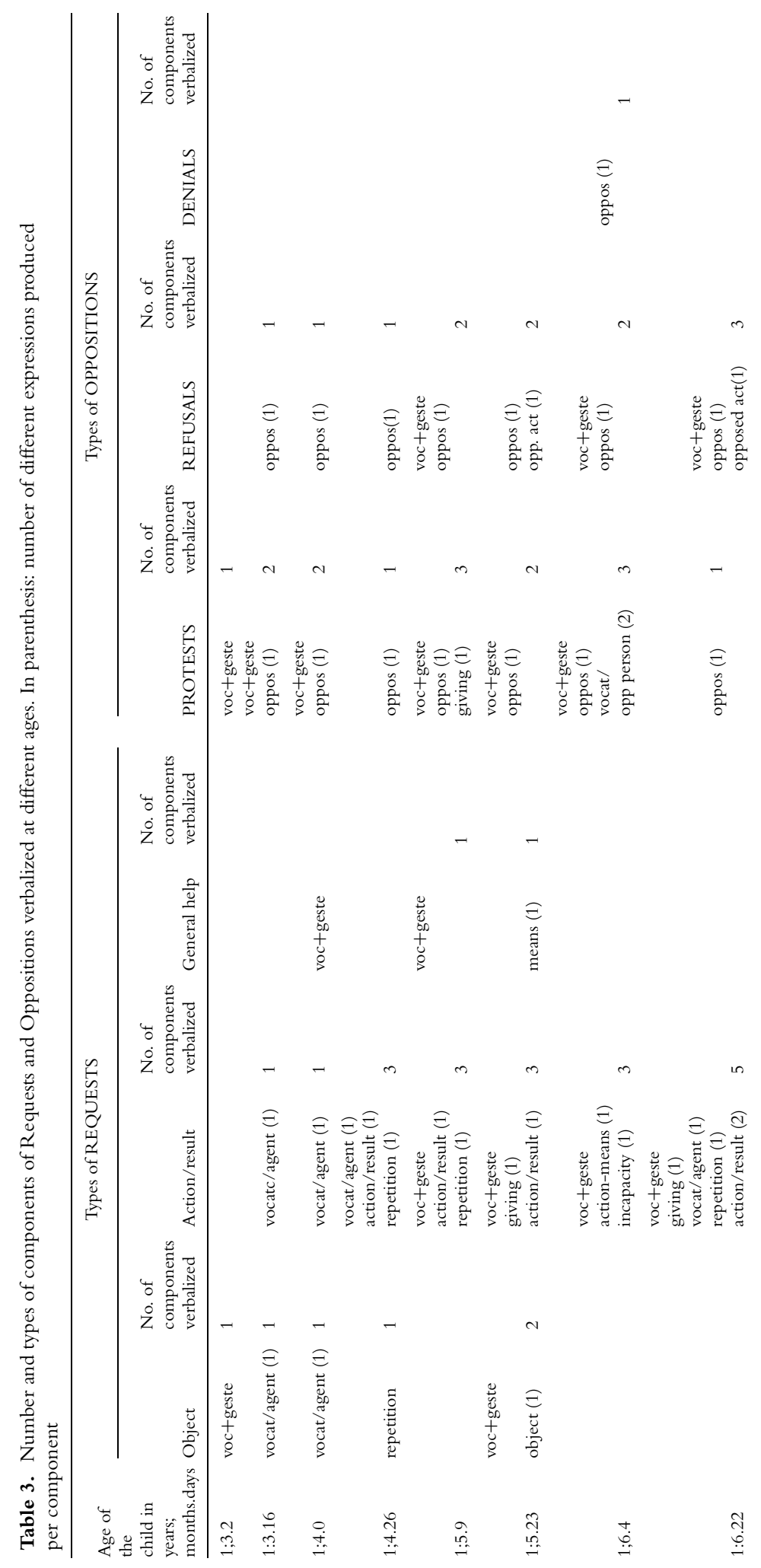


P1: MRM/SJS P2: MRM/SJS QC: MRM/SJS T1: MRM

KI076-15 September 15, 2004 16:24 Char Count $=0$

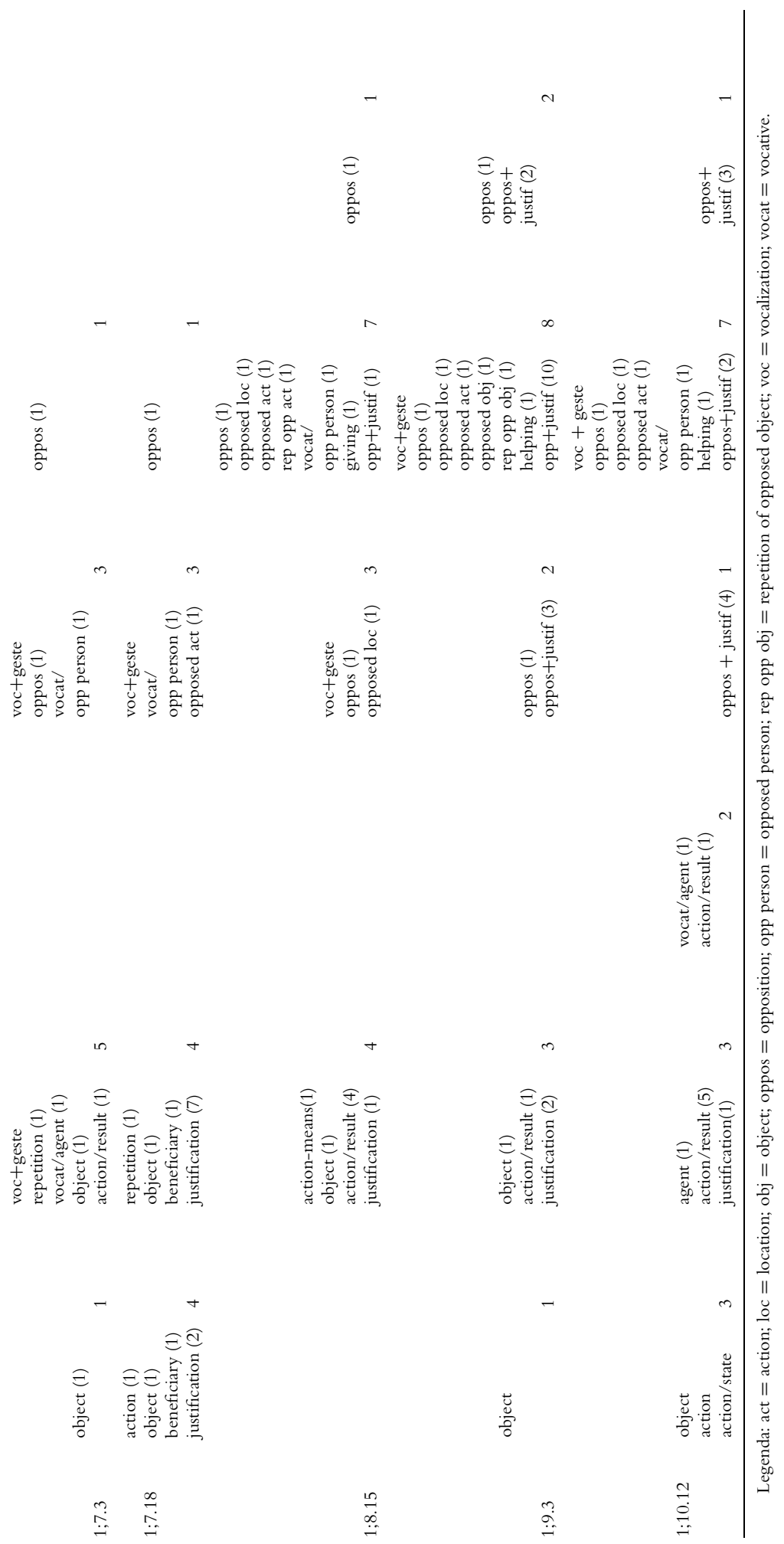


opposed person, action, and object, the action of giving or of helping to realize the opposed action. At 1;8.15 justifications appear, at first in refusals, and then in protests and denials. Their verbalization follows that of the opposition, and presents soon a variety of expressions adapted to the interactional situation at hand.

\section{Expressive options and the advent of justifications}

The verbal expression of justifications may constitute an early example of expressive option chosen by the child among simultaneously co-possible alternatives, for communicative adaptive purposes. This interpretation is suggested by the consideration that justifications are relational in nature. That is, they take their meaning and "raison d'être" from the act of which they provide the reason (Veneziano, 1999b, 2001). It follows, as a first argument, that when justifications are produced, request and oppositional acts are also in force. Requests find their outlet in the situational context through actions and gestures; oppositions, via a gesture and/or a simple negative particle. The verbalization of a justification in this context can thus be seen as a choice among simultaneously entertained perspectives. Second, justifications are mental constructions that refer to the past or to the future. They do not capture an aspect of the situation that may have attracted the child's attention, as this could have been the case for the verbalizations discussed under 2 above, and for the variety of verbalizations of request components. Mentally convoked, they are likely to be conceived simultaneously and in relation to other, contextually-bound, aspects of the event or act. Finally, justifications are directed to the addressee in order to convince him to do or not to dot something. They are supposed to be well suited to the communicative goals to be achieved. Indeed we have shown that, for oppositional acts, the production of a justification by the child makes the addressee more likely to give up on his initial intention and accept more readily the child's resistance (Veneziano, 2001).

\section{EXPRESSIVE ALTERNATIVES FOR ONE AND THE SAME COMMUNICATIVE INTENTION}

A movement from successively-centered to simultaneously-entertained different expressions can be uncovered also in the production of "successive single-word utterances" (SSWUs), one type of transitional phenomenon between the production of single and multi-word utterances (Barrett, 1989; Bloom, 1973; Greenfield \& Smith, 1976; Ochs, Schieffelin, \& Platt, 1979; Scollon, 1979; Veneziano et al., 1990; Veneziano, 1999a). Differently from the phenomena discussed above, in SSWUs the child produces at least two words to express one and the same communicative act, words that are either separated by the turn of another speaker or by an inter-words pause greater than half a second.

Different types of SSWUs have been found, characterized by different semantic and/or discourse properties, and it has been argued that they do not reflect the same capacities on the child's side. Among the different types of SSWUs reported, two main kinds are relevant for the present discussion, in that they capture well the change from successive to simultaneously envisaged expressions. These are across-turn 
conversationally-generated SSWUs - where the child produces a second word via the partner's intervention - and conversationally-unsustained SSWUs, in which the child's production of the two (or more) words is, instead, spontaneous and unsolicited (Veneziano, 1999a).

In one type of across-turn conversationally-generated SSWUs, it is the imitative uptake of a word contained in the mother's expansion of the child's previous utterance, that leads the child to produce an expression different from the one she had started with, as can be seen in the following example:

(1) Across-turn conversationally-generated SSWUs - imitative

The child has just placed a doll's hat on her head

$\begin{array}{ll}\text { Child }_{1} & : \quad \text { /'tet/ \# /'tet/ } \\ \text { 'head' \# 'head' } \\ \text { Mother }_{1}: & \begin{array}{l}\text { tu l'as mis sur ta tête le petit chapeau? } \\ \text { 'you put on your head the little hat?' }\end{array} \\ \text { Child }_{2} & : \quad \begin{array}{l}\text { /'pa'po / } \\ \text { chapeau 'hat' } \\ \text { c'est drôle ça! } \\ \text { Mother }\end{array} \\ & \text { 'that's funny!' }\end{array}$

In another type of across-turn conversationally-generated SSWUs, the new expression is produced by replying to a solicitation of the mother, as in example (2):

(2) Across-turn conversationally-generated SSWUs - discursive

The child places a baby doll into a plastic box and says:

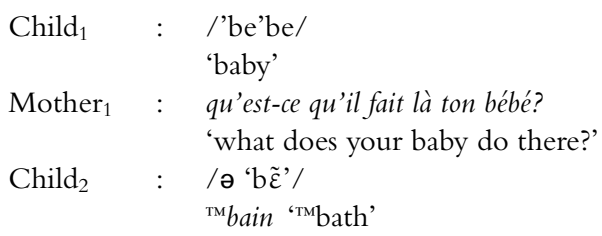

These two examples are particularly interesting because, somewhat later in the session, in an episode similar to example (1) the child starts out producing /'pa'po/ for

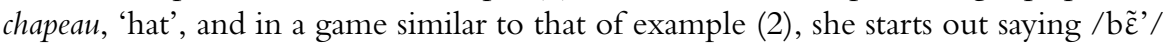
'bath'. This indicates that the relation established between the two verbal expressions within the conversational sequence, and through the intervening mother's utterance, seems to enrich the child's own repertoire of expressive choices and to have an effect on the child's verbalizations in subsequent similar occurrences.

Conversationally-unsustained SSWUs can be uttered across-turns or within-turns, but in both cases it is the child that spontaneously and in an unsolicited manner brings expressive variety to the situation by verbalizing different aspects of it (Veneziano, 1990a): 
\begin{tabular}{|lrcc} 
P1: MRM/SJS & P2: MRM/SJS & QC: MRM/SJS & T1: MRM \\
KI076-15 & September 15, 2004 & $16: 24$ & Char Count $=0$
\end{tabular}

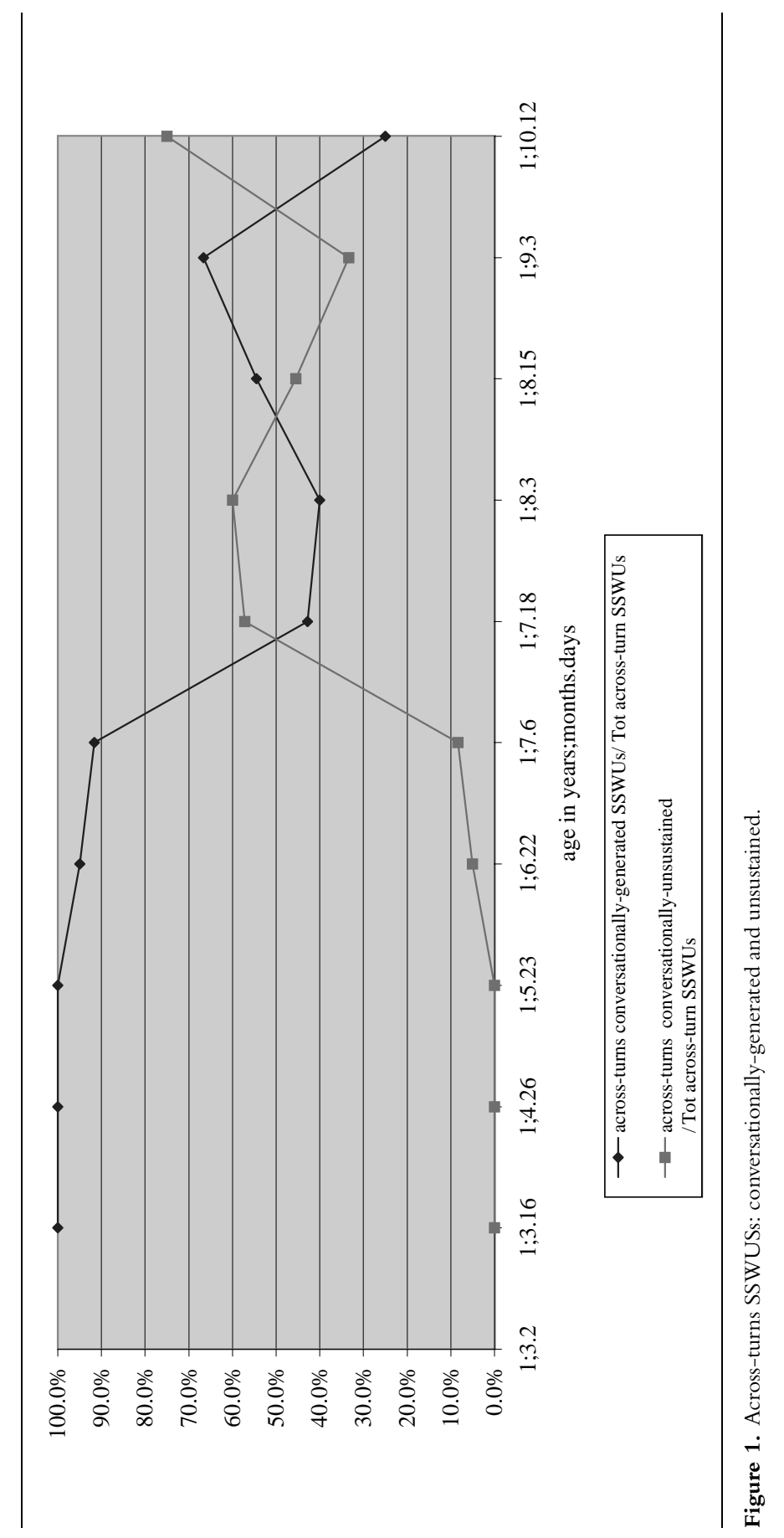


(3) Conversationally-unsustained SSWUs - across-turns

Mother and child look at a picturebook together. The child points towards the picture of a $\operatorname{dog}$

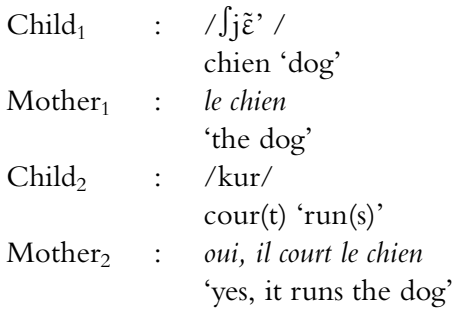

(4) Conversationally-unsustained SSWUs - within-turn

Mother and child look at a picturebook together. The child points towards the picture of a child gliding down a slide into a swimming pool

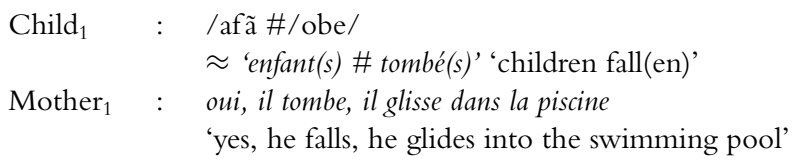

I would like to suggest that the production of SSWUs is an example of discoursedriven perspective-taking, in which the child comes to use different expressions to talk about a same event or communicative intent. At first, in across-turn conversationallygenerated SSWUs, constituting the great majority of the SSWUs that occur during the first months of SSWUs occurrence (see Figure 1), these expressions are produced successively and are probably not clearly related one to the other. The child verbalizes them focusing on different aspects of the event or communicative intent, through the unfolding of the conversational moves.

Then, in conversationally-unsustained SSWUs, the different verbal expressions arise in close temporal succession, if not simultaneously, and may be considered as mentally co-existing possibilities, verbalized one at the time for lack of all the abilities necessary for combinatorial speech. Children's growing capacity to take into account for verbalization more details of the situation (e.g., Ninio \& Snow, 1996) is likely to contribute to this change. These co-possible verbal expressions may eventually combine to give rise to a unit of a higher level:

(5) two-word utterance

Mother and child look at a picturebook together. The child points towards the picture of children fallen from a slide on the snow

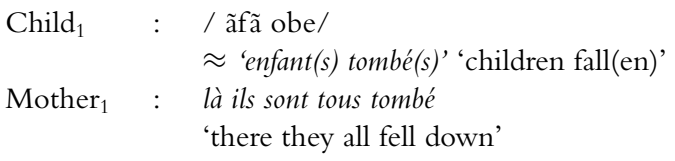


Table 4. Age of the child at the emergence and increase in frequency of successively and simultaneously entertained co-possible expressions

\begin{tabular}{lcc}
\hline & Emergence & Increase in frequency and variety \\
\cline { 2 - 3 } & \multicolumn{2}{c}{ Successively produced different expressions } \\
\hline $\begin{array}{l}\text { Verbalization of recurring acts/ } \\
\text { events }\end{array}$ & $1 ; 4.26$ & $1 ; 5.23-1 ; 6.22$ \\
$\begin{array}{l}\text { variety of verbalization in requests } \\
\text { conversationally-generated SSWUs }\end{array}$ & $1 ; 4.26$ & from $1 ; 6.22$ \\
& $1 ; 3.16$ & $1 ; 5.23-1 ; 7.6$ \\
justifications of communicative acts & $1 ; 5.23$ & from $1 ; 7.18$ \\
$\quad$ of request and opposition & $1 ; 6.22$ & $1 ; 7.18-1 ; 8.3$ \\
$\quad \begin{array}{l}\text { conversationally-unsustained } \\
\text { SSWUs }\end{array}$ & & \\
\hline
\end{tabular}

\section{DEVELOPMENTAL RELATIONS AMONG THE DIFFERENT PHENOMENA DISCUSSED}

Pulling together results from the previous analyses (see Table 4) it can be noticed that the appearance of different expressions in the case of similar recurring communicative acts - very similar recurring events and requests - and for the expression of one and the same communicative act - in across-turn conversationally-generated SSWUs - is observed at about the same time (around 1;4-1;5, with some advantage to the first observed occurrences of this type of SSWUs).

The increase in the frequency and in the variety of the expressions used occurs later and is also observed at about the same time for these different situations (it is observed around 1;6-1;7). As discussed above, for all these behaviors, it cannot be ascertained that the child entertains the different expressions simultaneously, conceiving them as co-possible options. They are most likely to be successive alternatives whose meanings are not yet related to that of the other alternative expressions within an overall system.

Those cases where it becomes reasonable to make this assumption - the production of justifications of requests and oppositions, and of conversationally-unsustained SSWUs appear later than the previous behaviors, and, like the latter, occur and increase at about the same time period.

\section{DISCUSSION: FROM SUCCESSIVE TO CO-POSSIBLE VERBAL EXPRESSIONS}

The temporal correspondences interestingly found among the appearance and further development of phenomena a priori unrelated among themselves, strongly support the hypothesis that the ability to take different verbal perspectives on a given event or on a given communicative act is related to progress in one underlying, general, cognitive development: that of entertaining mentally different possibilities at the same time. Moreover, they strongly suggest that simultaneously envisaged possibilities, entertained mentally, directly arise from successively-centered alternatives that the child constructs locally by focusing on different aspects of a given communicative situation. Successive focusing can itself be due to different sources. Children's growing ability to shift 
attention, to take into account for verbalization several aspects of the situation, and the increase in the availability of lexical items to express them, are certainly some of them. Another source is discourse, where shifts in attention and the verbalization of more than one aspect of the situation can arise through the conversational moves, as it is the case in across-turns conversationally-sustained SSWUs. These SSWUs have been considered to play a pivotal role in the change from single to multiword speech by allowing the child to produce a behavior of a higher level of functioning at a time when she is otherwise a single-word speaker (Veneziano, 1999a). The interpretation provided here, that takes into account the development of co-possible expressions, provides additional light to this hypothesis. As soon as the child, functioning as a speaker in certain types of discourse sequences, is provided the opportunity to shift perspectives on one and the same event or communicative act, she also becomes capable of taking different perspectives on recurring similar communicative acts, allowing different alternative expressions to make surface.

With increasing representational abilities, successive possible expressions can be anticipated simultaneously and become related options among which to choose, for overt expression, the one that suits best the communicative goals to be achieved. It is at this time that verbal expressions start to be related one to the other in an emerging linguistic system where meanings can be opposed to each other, compared or combined. The construction of relations among verbal expressions and situations of use, and the widening of the network of interrelations among verbal expressions and their meanings, is considered here to be a crucial step into the grasping of language as a system. This viewpoint, though derived from a somewhat different theoretical framework, rejoins other accounts of this developmental period, particularly that offered by Ninio (1994), and Ninio and Snow (1996), that conceive the change from "one-toone to many-to many mappings" as fundamentally related to a linguistic apprehension of language.

Simultaneously anticipated co-possible expressions are, at first, verbalized one at the time. Soon after, however, they may also be combined to give rise to meaningcoordinated multiword utterances. Expressive options become then a vehicle for overcoming the limitations of single-word utterances and one of the ways through which the child can enter multiword speech. Combinations may become, in turn, options in a new set of co-possible expressions.

The capacity to conceive different possibilities, and then to view them simultaneously as "co-possible" alternatives is considered here as a general underlying cognitive achievement necessary to the occurrence of a linguistically critical turning point, without being of course sufficient for such development to take place. This cognitive achievement allows children to start building up networks of lexical items and of expressions whose meaning and communicative function is partially determined by that of other items and functional expressions available in the set. Language knowledge starts to take the form of an incipient mentally constructed system of possibilities. Although the system is likely to be elaborated on the basis of concrete experiences, often of an interactional nature, the resultant knowledge consists of mentally conceived possibilities and depends on the way children relate and organize them internally. 
The essential characteristic of the progression described above, leading the child from successive (level " $n$ ") to simultaneously envisaged co-possibilities (level " $n+1$ ”), is that it is set in motion by conditions created by functioning typical of level " $n$ ". Functioning, viewed as the main motor of development, together with the necessity for mental constructions, can be considered the hallmarks of piagetian-type constructivist accounts of development ${ }^{6}$, and what distinguishes them from other, experiencesustained accounts.

\section{REFERENCES}

Antinucci, F. \& Parisi, D. (1973). Early language acquisition: A model and some data. In C.A. Ferguson \& D.I. Slobin (Eds.), Studies of child language development (pp. 607-619). New York: Holt, Rinehart \& Winston.

Barrett, M.D. (1981). The communicative function of early child language. Linguistics, 19, 273-305.

Barrett, M. (1989). Early language development. In A. Slater \& G. Bremner (Eds.), Infant development (pp. 211-241). London: Lawrence Erlbaum.

Berman, R.A. \& Slobin, D.I. (1994). Relating events in narrative: A cross-linguistic developmental study. Hillsdale, NJ: L. Erlbaum.

Bloom, L. (1973). One word at a time. The Hague: Mouton \& Co.

Clark, E.V. (1997). Conceptual perspective and lexical choice in acquisition. Cognition, 64, 1-37.

Greenfield, P.M. \& Smith, M. (1976). The structure of communication in early language development. New York: Academic Press.

Halliday, M.A.K. (1975). Learning how to mean: Explorations in the development of language. London: Edward Arnold.

Ninio, A. (1994). Expression of communicative intents in the single word period and the vocabulary spurt. In K. Nelson \& Z. Reger (Eds.), Children's language, Vol. 8. Hillsdale, NJ: L. Erlbaum.

Ninio, A. \& Snow, C.E. (1996). Pragmatic development. Boulder, CO: Westview Press.

Ochs, E. Schieffelin, B.B. \& Platt, M. (1979). Propositions across utterances and speakers. In E. Ochs \& B.B. Schieffelin (Eds.), Developmental pragmatics (pp. 251-268). New York: Academic Press.

Piaget, J. (1976/1978). Le comportement, moteur de l'évolution. Paris: Gallimard. (English translation: Behavior and evolution. New York: Pantheon Books, 1978).

Piaget, J. \& collaborateurs (1981/1987). Le possible et le nécessaire. Vol. 1: L'évolution des possibles chez l'enfant. Paris: P.U.F. (English translation: Possibility and necessity. Vol. 1: The role of possibility in cognitive development. Minneapolis: University of Minnesota Press, 1987).

Scollon, R. (1979). A real early stage: an unzippered condensation of a dissertation on child language. In E. Ochs \& B.B. Schieffelin (Eds.), Developmental pragmatics (pp. 215-227). New York: Academic Press.

Veneziano, E. (1990). Le rôle de la répétition dans le développement des énoncés à un mot aux énoncés à deux mots. Bulletin CILA, 51, 61-73.

Veneziano, E. (1999a). Early lexical, morphological and syntactic development in French: Some complex relations. Journal of Bilingualism, 3(2), 183-217.

Veneziano, E. (1999b). L'acquisition de connaissances pragmatiques: apprendre à expliquer. Revue PArole, 9/10, $1-28$.

Veneziano, E. (2001). Interactional processes in the origins of the explaining capacity. In K. Nelson, A Aksu-Koc \& C. Johnson (Eds.), Children's language, Vol. 10: Developing narrative and discourse competence (pp. 113-141). Mahwah, N.J.: L. Erlbaum.

Veneziano, E. \& Sinclair, H. (1995). Functional changes in early child language: The appearance of references to the past and of explanations. Journal of Child Language, 22, 557-581.

Veneziano, E. \& Sinclair, H. (2000). The changing status of "filler syllables" on the way to grammatical morphemes. Journal of Child Language, 27, 1-40.

Veneziano, E., Sinclair, H., \& Berthoud, I. (1990). From one word to two words: Repetition patterns on the way to structured speech. Journal of Child Language, 17, 633-650.

${ }^{6}$ A suggestive indication for the prominent place given to functioning by Piaget is provided by the title of one of his books (1976/1978), "Le comportement, moteur de l'evolution" (translated in English simply as "Behavior and Evolution"). 